\title{
Current asthma contributes as much as smoking to chronic bronchitis in middle age: a prospective population-based study
}

This article was published in the following Dove Press journal:

International Journal of COPD

16 August 2016

Number of times this article has been viewed

\author{
Shyamali C Dharmage,' \\ Jennifer L Perret, ${ }^{1,2}$ \\ John A Burgess,' \\ Caroline J Lodge,' \\ David P Johns, ${ }^{3}$ \\ Paul S Thomas, ${ }^{4}$ Graham \\ G Giles, ${ }^{1,5}$ John L Hopper, ${ }^{1,6}$ \\ Michael J Abramson, 7,8 \\ E Haydn Walters, ${ }^{3,9}$ \\ Melanie C Matheson' \\ 'Allergy and Lung Health Unit, Center \\ for Epidemiology and Biostatistics, \\ The University of Melbourne, \\ ${ }^{2}$ Institute for Breathing and Sleep \\ (IBAS), Melbourne, VIC, ${ }^{3 " B r e a t h e}$ \\ Well" Center of Research Excellence \\ for Chronic Respiratory Disease \\ and Lung Ageing, School of Medicine, \\ University of Tasmania, Hobart, TAS, \\ ${ }^{4}$ Inflammation and Infection Research, \\ Faculty of Medicine, University of New \\ South Wales, Sydney, NSW, ${ }^{5}$ Cancer \\ Epidemiology Center, Cancer Council \\ Victoria, Melbourne, VIC, Australia; \\ ${ }^{6}$ Department of Public Health, Seoul \\ National University, Seoul, South \\ Korea; ${ }^{7}$ Allergy, Immunology and \\ Respiratory Medicine, The Alfred \\ Hospital, Melbourne, ${ }^{8}$ School of Public \\ Health and Preventive Medicine, \\ Monash University, Melbourne, VIC, \\ ${ }^{9}$ School of Medicine, University of \\ Tasmania, Hobart, TAS, Australia
}

Correspondence: Shyamali C Dharmage Center for Epidemiology and Biostatistics, Melbourne School of Population and Global Health, Level 3, 207 Bouverie St, The University of Melbourne, Melbourne, VIC 30I0, Australia

Tel +6I 383440737

Fax +6I 393495815

Email s.dharmage@unimelb.edu.au
Background and objective: Personal smoking is widely regarded to be the primary cause of chronic bronchitis (CB) in adults, but with limited knowledge of contributions by other factors, including current asthma. We aimed to estimate the independent and relative contributions to adult $\mathrm{CB}$ from other potential influences spanning childhood to middle age.

Methods: The population-based Tasmanian Longitudinal Health Study cohort, people born in 1961, completed respiratory questionnaires and spirometry in $1968(n=8,583)$. Thirty-seven years later, in 2004, two-thirds responded to a detailed postal survey $(n=5,729)$, from which the presence of CB was established in middle age. A subsample $(n=1,389)$ underwent postbronchodilator spirometry between 2006 and 2008 for the assessment of chronic airflow limitation, from which nonobstructive and obstructive $\mathrm{CB}$ were defined. Multivariable and multinomial logistic regression models were used to estimate relevant associations.

Results: The prevalence of CB in middle age was $6.1 \%$ (95\% confidence interval $[\mathrm{CI}]: 5.5,6.8)$. Current asthma and/or wheezy breathing in middle age was independently associated with adult CB (odds ratio [OR]: 6.2 [95\% CI: 4.6, 8.4]), and this estimate was significantly higher than for current smokers of at least 20 pack-years (OR: 3.0 [95\% CI: 2.1, 4.3]). Current asthma and smoking in middle age were similarly associated with obstructive $\mathrm{CB}$, in contrast to the association between allergy and nonobstructive $\mathrm{CB}$. Childhood predictors included allergic history (OR: 1.3 [95\% CI: 1.1, 1.7]), current asthma (OR: 1.8 [95\% CI: 1.3, 2.7]), "episodic" childhood asthma (OR: 2.3 [95\% CI: 1.4, 3.9]), and parental bronchitis symptoms (OR: 2.5 [95\% CI: 1.6, 4.1]).

Conclusion: The strong independent association between current asthma and CB in middle age suggests that this condition may be even more influential than personal smoking in a general population. The independent associations of childhood allergy and asthma, though not childhood bronchitis, as clinical predictors of adult $\mathrm{CB}$ raise the possibility of some of this burden having originated in childhood.

Keywords: nonobstructive chronic bronchitis, obstructive chronic bronchitis, current asthma, personal smoking, allergy history

\section{Introduction}

Over the last 50 years, there has been relatively little progress related to the etiology and diagnosis of chronic bronchitis (CB) in adults. Bronchial mucus hypersecretion is the classically accepted cardinal feature, which usually manifests as a productive cough on most days during at least three consecutive months for 2 or more successive years. ${ }^{1,2}$ Nonobstructive or simple chronic bronchitis (NCB) contrasts with "chronic obstructive bronchitis", which is included within the definition of chronic obstructive pulmonary disease (COPD). ${ }^{3}$ Clinicians and researchers have generally focused on 
obstructive $\mathrm{CB}$ because of its high mortality, ${ }^{4}$ propensity for acute COPD exacerbations, and its association with excessive forced expiratory volume in 1 second decline in more advanced COPD. ${ }^{5}$ Nonetheless, NCB is not a trivial condition, affecting an estimated nine million individuals in the US, predisposing them to recurrent chest infections, absenteeism from work, a poorer quality of life, and possibly increased mortality. ${ }^{6}$ Thus, regardless of whether it is obstructive or not, adult $\mathrm{CB}$ has substantial public health implications.

Bronchial infection, air pollution, personal and secondhand tobacco smoke exposure, occupation, heredity, allergy, asthma, and socioeconomic status have been proposed to be etiological factors for CB. ${ }^{2,7}$ The assessment of the relative importance of these individual factors has been challenging, ${ }^{7}$ such that personal smoking is widely regarded as the major risk factor, and there is often little recognition of other potential factors, including allergies. ${ }^{2,8,9}$ Likewise, the precise role of childhood and current adult asthma remains the key areas of interest, particularly when associated with CB-related COPD. ${ }^{10}$ Prospectively collected data from childhood to middle age is relatively scarce thereby limiting the investigation of these questions. Previous data relate to a much higher prevalence of smoking 50 years ago, especially for males, and there is a lack of more recent studies that have addressed the multifactorial nature of adult $\mathrm{CB}$.

By using longitudinal data from the prospective follow-up of the Tasmanian Longitudinal Health Study (TAHS), we evaluated the association between independent host and environmental factors in childhood (at the age of 7 years) and middle age (in mid-forties) for having $\mathrm{CB}$ in mid-adult life. We further investigated by $\mathrm{CB}$ phenotypes, and hereafter refer to $\mathrm{CB}$ in middle age as simply "adult CB".

\section{Materials and methods Study design and population}

Subjects were participants in the 5th decade follow-up of the TAHS, which is a population-based family study of 45,900 participants that commenced in 1968. The methods for the baseline and subsequent follow-up studies have been published. ${ }^{11-17}$ Briefly, the "probands" who were born in 1961 and schooled in Tasmania in 1968 ( $n=8,583$ [99\%]) were studied by analyzing questionnaire responses and by performing spirometry when they were 7 years old. Respiratory questionnaires were also completed by parents $(n=17,035)$ and siblings $(n=21,035)$. Of the original 8,583 probands, to 7,312 (85\%), who were retraced between 2002 and 2004, a detailed postal survey was then sent out when the probands were aged in their early-to-mid forties. A total of 5,729 (78\%) responded, and this represented two-thirds (67\%) of the original cohort. Respondents were chosen to participate in a clinical laboratory study based on either participation in multiple follow-up studies (including the 1974 clinical study and/or 1992 follow-up visits) or the presence of adult asthma and/or CB. Of the 2,373 invited, 1,389 (58.5\%) participated. The main analysis here was based on the questionnaire data collected in 1968 and $2004(n=5,729)$, with the subsequent analysis of post-bronchodilator (BD) spirometry and skin prick testing for those who participated in the clinical study between 2006 and $2008(n=1,389)$.

\section{Data collection methods}

The predicted values for spirometry when participants were aged 7 years and in middle age were calculated using reference values from the Global Lung Initiative. ${ }^{18}$ Parentcompleted school medical records, which included history of childhood infections and immunizations, were accessed at the time of the 2004 postal survey.

\section{Clinical definitions}

\section{Outcomes}

Adult chronic bronchitis (adult CB) was defined by a series of affirmative responses to the 2004 postal survey questions "Do you usually have phlegm in your chest when you do not have a cold?"; "Are there months in which you have phlegm in your chest on most days?"; "Do you bring up this phlegm on most days for at least 3 months each year?"; and if yes, then "For how many years have you had this phlegm?" This was followed by three options: "less than 2 years; 2-5 years; more than 5 years", of which the latter two fulfilled the Lancet criteria. ${ }^{1}$

Obstructive $\mathrm{CB}$ was defined similar to that used for defining adult $\mathrm{CB}$, but in the context of post-BD airflow obstruction in the 2006-2008 laboratory study, which was defined by the lower limit of normal predicted values and expressed as $z$-scores. ${ }^{18,19}$

\section{Exposures}

Asthma-ever, based on participant recall, was defined by an affirmative response to the 2004 postal survey question, "Have you, at any time in your life, suffered from attacks of asthma or wheezy breathing?" Current adult asthma was defined as a history of asthma and/or wheezy breathing, when without a cold, in the last 12 months. ${ }^{20}$

Allergy history in 1968 was defined by the affirmative response by parents and/or guardian to a history of food or medicine allergy, childhood eczema, and hives. Allergy history 
in 2004 was a history of allergy that was recalled by participants with regard to ever-eczema, hay fever, and/or allergy to food, medicine, dust, pollens, and/or animals.

Personal active smoking in 2004 was defined by the question "In your lifetime, have you smoked at least 100 cigarettes or equal amounts of cigars, pipes, or other tobacco product?", and was expressed by smoking status (never, past, and current), and smoking duration and intensity (pack-years, where 1 pack-year is equivalent to smoking 20 cigarettes per day for 1 year).

Current childhood asthma was defined by episodes of "asthma or wheezy breathing" within the preceding 12 months. A modified classification for childhood asthma (and/or wheezy breathing) severity was based on the Australian National Asthma Council document of 2006 and was determined by the number, frequency, and duration of childhood asthma and/or wheezy breathing episodes in 1968. ${ }^{17}$ Specifically "episodic" asthma included either those with asthma episodes up to 3 months that lasted between a week to a month or fortnight to monthly episodes that lasted for a week.

Childhood bronchitis was defined by an affirmative parental response to the 1968 question, "Has he/she at any time in his/her life suffered from attacks of bronchitis or attacks of cough with sputum (phlegm) in the chest ('loose' or 'rattly' cough)?' Recurrent childhood bronchitis was defined by a threshold of two childhood episodes, with increasing severity categories predetermined by the survey question, "Since the attacks began, approximately how many has he/she had altogether?" Childhood chronic bronchitis was defined by the response, "never free of loose cough for more than a day or two".

See Supplementary materials for other definitions, including skin prick testing.

\section{Statistical analysis}

All analyses were carried out using the statistical software Stata (release 12; Stata Corporation, College Station, TX). Overall prevalence in the postal survey was based on the entire cohort, whereas sampling weights were used for the prevalence in the laboratory study. Logistic regression was used to examine the associations between the exposures and current bronchitis as a categorical variable. The multivariable models were adjusted for a priori confounders and additionally adjusted for confounders that changed the estimates of the associations by at least $10 \%$ (Supplementary materials). Associations for variables not included in the models are summarized in Table S1.
Independent associations were calculated using models containing exposure variables adjusted for one another. Biologically plausible interactions (or multiplicative effects) were investigated by including current asthma, smoking, ${ }^{16}$ and sex, and results were stratified if a statistical interaction was present. Those with missing data were excluded from individual analyses, consistent with complete case analysis. A conventional cut-off of $P<0.05$ was used to determine statistical significance. Corrections for multiple comparisons were not applied as there were more associations than one would expect by chance, and almost all analyses were based on findings previously reported in the literature.?

\section{Ethics}

This study was approved by the Human Ethics Review Committees at The Universities of Melbourne (approval number 040375), Tasmania (040375.1), New South Wales (08094), the Alfred Hospital (1118/04), and Royal Brisbane \& Women's Hospital Health Service District (2006/037). Written informed consent was obtained from all participants.

\section{Results}

\section{Descriptive characteristics of participants}

The mean age of the participants at the 2004 postal survey was 43 (standard deviation 0.8 ) years (Table 1). The prevalence of self-reported CB in this survey (hereafter referred to simply as adult $\mathrm{CB}$ ) was $6.1 \%$ (95\% confidence interval $[\mathrm{CI}]: 5.5,6.8)$. There was modest evidence that the prevalence was higher for males than females $(6.7 \%$ [5.8-7.7] versus 5.5\% [4.7-6.4], $P=0.052$ ).

The lung function data from the 2006-2008 laboratory study have been published (at the mean age of 45 years), where $10 \%(n=131)$ fulfilled the criterion for post-BD airflow obstruction. ${ }^{16}$ Of those with adult $\mathrm{CB}, 19 \%(\mathrm{n}=22 / 117)$ also had post-BD airflow obstruction of any severity, but only $4.3 \%(n=5 / 117)$ had at least moderately severe chronic airflow limitation.

Higher proportions of participants with adult $\mathrm{CB}$ had asthma and allergy in childhood and middle age than those without adult CB (Table 1). Of participants in the 1968 survey, 3,170 (39\%) reported at least two episodes of childhood bronchitis and 1,357 (17\%) reported a history of asthma and/or wheezy breathing when they were 7 years old. A history of childhood asthma was present in 1,130 (36\%) of those reporting recurrent bronchitis. Half of those with childhood asthma had a history of allergy $(n=689,50 \%)$. The prevalence of these childhood factors were similar to participants lost to follow-up. 
Table I Main characteristics of all TAHS participants (and nonresponders) to the 2004 postal survey, stratified by adult chronic bronchitis

\begin{tabular}{|c|c|c|c|c|}
\hline \multirow[t]{3}{*}{ Clinical characteristics } & \multicolumn{3}{|c|}{ Self-reported adult CB } & \multirow[t]{3}{*}{ Nonresponders $(n=2,720)^{a}$} \\
\hline & \multicolumn{2}{|l|}{$(\mathrm{N}=5,565[\%])$} & \multirow[t]{2}{*}{$P$-value } & \\
\hline & No $(n=5,224[94])$ & Yes (n=34I [6]) & & \\
\hline \multicolumn{5}{|l|}{ Demographics } \\
\hline Age in years, mean (SD) & $42.8(0.9)$ & $42.9(0.9)$ & 0.771 & - \\
\hline Sex (male) & $2,673(5 \mathrm{I})$ & $193(57)$ & 0.052 & $\mathrm{I}, 379(5 \mathrm{I})$ \\
\hline \multicolumn{5}{|l|}{ Cigarette smoking } \\
\hline Nonsmokers & $2,140(42)$ & $79(24)$ & $<0.001$ & - \\
\hline Ex-smoker $<20$ pack-years & $\mathrm{I}, \mathrm{I} 73(23)$ & $46(14)$ & $<0.001$ & - \\
\hline Ex-smoker $>20$ pack-years & $353(7)$ & $13(4)$ & 0.034 & - \\
\hline Current $<20$ pack-years & $701(14)$ & $51(15)$ & 0.421 & - \\
\hline Current $>20$ pack-years & $708(14)$ & $143(43)$ & $<0.001$ & - \\
\hline \multicolumn{5}{|l|}{ Asthma and/or wheezy breathing } \\
\hline Asthma 1968 & $889(17)$ & $92(27)$ & $<0.001$ & $405(15)$ \\
\hline \multicolumn{5}{|l|}{ Asthma 2004} \\
\hline None & $3,05 \mid(58)$ & $72(2 \mathrm{I})$ & $<0.00 \mathrm{I}$ & - \\
\hline Remitted & I,I54 (22) & $42(12)$ & $<0.001$ & - \\
\hline Current & $1,017(19)$ & $227(66)$ & $<0.001$ & - \\
\hline \multicolumn{5}{|l|}{ Allergic history } \\
\hline Any allergy 1968 & $\mathrm{I}, 732(34)$ & $139(42)$ & 0.002 & $856(33)$ \\
\hline Any allergy 2004 & $2,475(47)$ & $224(66)$ & $<0.001$ & - \\
\hline \multicolumn{5}{|l|}{ Childhood bronchitis } \\
\hline At least two episodes & $2,043(40)$ & 147 (45) & 0.071 & $958(36)$ \\
\hline At least ten episodes & $434(8)$ & $47(14)$ & 0.015 & $218(8)$ \\
\hline
\end{tabular}

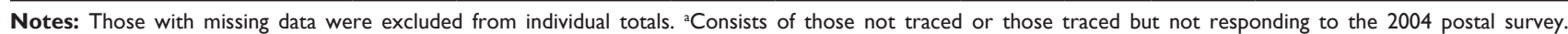
Mean comparison test (age only) and cohort study summary statistics using Stata 12 SE was used to obtain the $P$-values.

Abbreviations: TAHS, Tasmanian Longitudinal Health Study; CB, chronic bronchitis; SD, standard deviation.

\section{Independent associations between smoking, asthma, and adult $\mathrm{CB}$}

Of all ever smokers, a greater proportion of current smokers of at least 20 pack-years had adult CB (42\% [95\% CI: 37-47]) compared with $14 \%$ without adult CB ([95\% CI: 13-15], $P<0.0001)$. Current smoking at least 20 pack-years, and a 40 pack-year history of smoking regardless of smoking status were both associated with at least a three-fold increase in the odds of adult $\mathrm{CB}$ in a multivariable model $(P<0.001$ and $P=0.005$, respectively) (Table 2 ). No association was seen in past smokers, regardless of pack-year history, and there was a dose-response relationship with the univariable smoking trend $(P$ for trend $<0.001$ ).

For current asthma and/or wheezy breathing, the strength of association was significantly higher than the estimate for current smoking at least 20 pack-years (odds ratio [OR]: 6.19 [95\% CI: $4.55,8.42$ ] versus 3.03 [95\% CI: 2.14 , 4.30]). However, no interaction was observed between the effects of current asthma and current smoking on adult CB $(P=0.655)$.

\section{Specific associations between allergy history and adult CB}

A history of any allergy by middle age was independently associated with adult CB (OR: 2.07 [95\% CI: 1.57, 2.73],
$P<0.001$ ) (Table 3). Specific positive associations between individual allergy histories and adult $\mathrm{CB}$ included animal allergy $(P=0.001)$, pollen allergy $(P<0.001)$, food allergy $(P=0.003)$, ever-eczema $(P<0.001)$, and hay fever $(P<0.001)$ (Table 3$)$. The strength of associations between allergy history and adult $\mathrm{CB}$ was significantly lower than the estimate for current asthma, either when analyzed as a combined variable or in separate regression models. This contrasts with a lack of association between adult atopic sensitization and adult CB (OR: 1.20 [95\% CI: 0.83, 1.72], $P=0.330, \mathrm{n}=1,232$ ), which remained nonsignificant after adjusting for asthma status.

\section{Independent associations between early life factors and adult $C B$}

We found childhood hives (urticaria) $(P=0.037)$, any history of childhood allergy $(P=0.018)$, "episodic" childhood asthma $(P=0.002)$, current childhood asthma $(P=0.001)$, and male sex $(P=0.009)$ to be independently associated with adult CB (Table 4). Parental bronchitis when participants were aged 7 years old was also significant $(P \leq 0.001)$, with the strength of association for two affected parents being statistically greater than the estimate for personal allergy history. Results for parental bronchitis were essentially unchanged when adjusted for parental smoking. 
Table 2 Independent associations between clinical characteristics and CB in middle age

\begin{tabular}{|c|c|c|c|c|}
\hline \multirow[t]{2}{*}{ Clinical characteristics } & \multicolumn{4}{|c|}{ Self-reported adult CB $(\mathrm{N}=4,949[\%])$} \\
\hline & No $(n=4,658[94])$ & Yes $(n=29 \mid[6])$ & Univariable $P$ for trend & Adjusted OR $(95 \% \mathrm{Cl})^{\mathrm{a}}$ \\
\hline Male sex & $2,377(5 \mathrm{I})$ & $168(58)$ & - & $1.46(1.12,1.90)^{*}$ \\
\hline Combined smoking history & & & $<0.001$ & \\
\hline None & $1,986(43)$ & $78(27)$ & & I \\
\hline Ex-smoker $<20$ pack-years & $1,094(23)$ & $43(15)$ & & $0.99(0.67,1.46)$ \\
\hline Ex-smoker $>20$ pack-years & $331(7)$ & $12(4)$ & & $0.86(0.44,1.59)$ \\
\hline Current $<20$ pack-years & $625(13)$ & $42(14)$ & & $1.54(1.03,2.32)^{*}$ \\
\hline Current $>20$ pack-years & $622(13)$ & $116(40)$ & & $3.03(2.14,4.30)^{* *}$ \\
\hline Smoking status & & & $<0.001$ & \\
\hline Never & $\mathrm{I}, 986(43)$ & $77(26)$ & & I \\
\hline Past & $\mathrm{I}, 425(3 \mathrm{I})$ & $56(19)$ & & $0.62(0.30,1.30)$ \\
\hline Current & $\mathrm{I}, 246(27)$ & $158(54)$ & & $1.36(0.64,2.88)$ \\
\hline Pack-year history & & & $<0.001$ & \\
\hline None & $2,283(49)$ & $85(29)$ & & 1 \\
\hline Up to 10 pack-years & $828(18)$ & $42(14)$ & & $\mathrm{I} .47(0.69,3.1 \mathrm{I})$ \\
\hline Between 10 and 20 pack-years & $638(14)$ & $38(13)$ & & $1.38(0.64,2.98)$ \\
\hline Between 20 and 40 pack-years & $747(16)$ & $85(29)$ & & $1.90(0.90,4.00)$ \\
\hline$>40$ pack-years & $162(3)$ & $40(14)$ & & $3.19(1.42,7.17)^{* * * *}$ \\
\hline Asthma/wheezy breathing & & & $<0.001$ & \\
\hline Never & $2,723(58)$ & $65(22)$ & & 1 \\
\hline Remitted & $\mathrm{I}, 035(22)$ & $38(13)$ & & $1.29(0.85,1.96)$ \\
\hline Current (last I 2 months) & $900(19)$ & $188(65)$ & & $6.19(4.55,8.42)^{* *}$ \\
\hline Allergy history & & & - & \\
\hline Any history & $2,218(48)$ & $195(67)$ & & $2.07(1.57,2.73)^{* *}$ \\
\hline Passive smoking & & & $<0.001$ & \\
\hline None & $3,490(75)$ & $166(57)$ & & 1 \\
\hline Between I and 3 hours/day & $735(16)$ & $58(20)$ & & $1.05(0.75,1.47)$ \\
\hline At least 4 hours/day & $433(9)$ & $67(23)$ & & I.3। $(0.92,1.87)$ \\
\hline Parental bronchitis at least every 3 years in 1968 & & & - & \\
\hline Neither parent & 4,07I (87) & $232(80)$ & & 1 \\
\hline Either or both & $587(13)$ & $59(20)$ & & $1.13(0.82,1.57)$ \\
\hline
\end{tabular}

Notes: Those with missing data were excluded from individual analyses. ${ }^{\text {aAll }}$ exposure variables are adjusted for one another in addition to participant education and occupation (estimates included in Table SI). The combined smoking variable was initially used, then substituted for separate smoking status and pack-year variables; $* P<0.05$; $* * P<0.001 ; * * * P<0.01$.

Abbreviations: $\mathrm{CB}$, chronic bronchitis; $\mathrm{Cl}$, confidence interval; $\mathrm{OR}$, odds ratio.

Table 3 Multivariable associations between allergy history and CB in middle age

\begin{tabular}{|c|c|c|c|}
\hline \multirow[t]{2}{*}{ Allergy history in 2004} & \multicolumn{3}{|c|}{ Self-reported adult CB (N=4,949 [\%]) } \\
\hline & No $(n=4,658[94])$ & Yes $(n=29 ![6])$ & Adjusted OR $(95 \% \mathrm{CI})^{\mathrm{a}}$ \\
\hline Any history & $2,218(48)$ & $195(67)$ & $2.07(1.57,2.73)^{*}$ \\
\hline Food allergy & $542(10)$ & $62(18)$ & $1.80(1.22,2.63)^{* *}$ \\
\hline Medicine allergy & $825(16)$ & $67(20)$ & $1.19(0.83,1.70)$ \\
\hline \multirow[t]{3}{*}{ Dust allergy } & $787(15)$ & $104(31)$ & Males: $2.04(1.23,3.38)^{* * *}$ \\
\hline & & & Females: $2.62(1.67,4.12)^{*}$ \\
\hline & & & $P[$ interaction $]=0.017$ \\
\hline Animal allergy & $536(10)$ & $66(19)$ & $1.85(1.26,2.69)^{* * *}$ \\
\hline Pollen allergy & $\mathrm{I}, 525(29)$ & $158(46)$ & $\mathrm{I} .8 \mathrm{I}(\mathrm{I} .35,2.43)^{*}$ \\
\hline Ever eczema & $1,859(36)$ & $173(5 \mid)$ & $1.67(1.26,2.22)^{*}$ \\
\hline Hay fever & $2,547(49)$ & $233(69)$ & $1.76(1.30,2.40)^{*}$ \\
\hline
\end{tabular}

Notes: Those with missing data were excluded from individual analyses. ${ }^{2}$ Adjusted for male sex, current wheezing 2004, smoking (status and pack-years), parental bronchitis 1968, highest attained educational level, and participant occupation 2004; $* P<0.001 ; * * P<0.05 ; * * * P<0.01$.

Abbreviations: $\mathrm{CB}$, chronic bronchitis; $\mathrm{Cl}$, confidence interval; $\mathrm{OR}$, odds ratio. 
Table 4 Independent associations between early-life factors and CB in middle age

\begin{tabular}{|c|c|c|c|c|}
\hline \multirow{2}{*}{$\begin{array}{l}\text { Clinical characteristics when } \\
\text { participants were aged } 7 \text { years }\end{array}$} & \multicolumn{4}{|c|}{ Self-reported adult CB (N=5, I $70[\%])$} \\
\hline & No $(n=4,862[94])$ & Yes $(n=308[6])$ & Univariable $P$ for trend & Adjusted OR $(95 \% \mathrm{Cl})^{\mathrm{a}}$ \\
\hline Male sex & $2,485(5 \mathrm{I})$ & $179(58)$ & - & $1.39(1.09,1.77)^{*}$ \\
\hline \multicolumn{5}{|l|}{ Childhood bronchitis } \\
\hline None & $2,492(52)$ & $133(45)$ & 0.001 & 1 \\
\hline I episode only & $384(8)$ & $30(10)$ & & $1.38(0.91,2.08)$ \\
\hline $2-5$ episodes & $990(21)$ & $54(18)$ & & $0.85(0.60,1.19)$ \\
\hline $5-10$ episodes & $519(11)$ & $36(12)$ & & $0.94(0.62,1.42)$ \\
\hline I I-20 episodes & $235(5)$ & $23(8)$ & & $1.20(0.72,2.00)$ \\
\hline$>20$ episodes & $165(3)$ & $20(7)$ & & $1.33(0.75,2.35)$ \\
\hline Chronic symptoms & $3 I(I)$ & $3(I)$ & & $1.36(0.45,4.07)$ \\
\hline \multicolumn{5}{|l|}{ Asthma status } \\
\hline No asthma & $4,046(83)$ & $227(74)$ & $<0.001$ & I \\
\hline Remitted asthma & $225(5)$ & $18(6)$ & & $1.17(0.71,1.92)$ \\
\hline Current asthma & $495(10)$ & $59(20)$ & & $1.84(1.26,2.68)^{*}$ \\
\hline \multicolumn{5}{|l|}{ Asthma severity } \\
\hline No asthma & $4,046(83)$ & $227(74)$ & $<0.001$ & 1 \\
\hline "Infrequent intermittent" & $406(8)$ & $36(12)$ & & $1.39(0.92,2.10)$ \\
\hline "Frequent intermittent" & $25(I)$ & $2(1)$ & & $0.49(0.64,3.78)$ \\
\hline "Episodic" & $139(3)$ & $22(7)$ & & $2.32(1.38,3.92)^{*}$ \\
\hline “Moderate-to-severe persistent" & $21(0.4)$ & $3(I)$ & & $1.81(0.5 \mathrm{I}, 6.45)$ \\
\hline Allergy history & & & - & \\
\hline Any allergy & $1,627(33)$ & $133(43)$ & & $1.35(1.05,1.73)^{* *}$ \\
\hline Hives, at least once & $963(20)$ & $84(27)$ & & $1.34(\mathrm{I} .02, \mathrm{I} .76)^{* *}$ \\
\hline Bronchial symptoms reported by parent & & & $<0.001$ & \\
\hline Neither parent & $3,84 I(79)$ & $206(67)$ & & 1 \\
\hline One or either parent & $871(18)$ & $79(26)$ & & $1.61(1.22,2.13)^{*}$ \\
\hline Both parents & $150(3)$ & $23(7)$ & & $2.5 \mathrm{I}(1.56,4.06)^{* * * *}$ \\
\hline
\end{tabular}

Notes: Those with missing data were excluded from individual analyses. aAll exposure variables are adjusted for one another in addition to paternal occupation (estimates included in Table SI). The "any allergy" variable was initially used, then hives only was substituted. Similarly, asthma status and asthma severity as well as bronchitis frequency and chronicity were substituted with other variables retained; $* P<0.01$ I; $* P<0.05 ; * * * P<0.00$ I.

Abbreviations: $\mathrm{CB}$, chronic bronchitis; $\mathrm{Cl}$, confidence interval; $\mathrm{OR}$, odds ratio.

The univariable association between childhood bronchitis of more than ten episodes and adult CB (OR: 1.95 [95\% CI: $1.39,2.75], P<0.001)$ was not apparent after adjustment for childhood asthma severity. Similarly, the univariable association between exposure to maternal smoking and adult $\mathrm{CB}$ (OR: 1.38 [95\% CI: 1.10, 1.74], $P=0.005$ ) was not present after adjustment for parental history of bronchitis symptoms (Table S1). There was no univariable association with paternal smoking, and no interaction between the effects of childhood asthma and bronchitis on adult CB ( $P$ for interaction $=0.389$ ).

\section{Independent associations for NCB and obstructive CB}

In the sample that subsequently underwent post-BD spirometry $(n=1,389)$, the weighted prevalence of adult NCB was $5.2 \%, 5.6 \%$ for spirometrically defined COPD in the absence of adult $\mathrm{CB}$ and $0.8 \%$ for the combination, that is, adult obstructive CB. In a model that included only adult smoking, asthma, and allergy exposures (Table 5), current smoking, especially of at least 20 pack-years, was associated with all of these outcomes. Current asthma was associated with spirometrically defined COPD $(P<0.001)$, with or without a reported history of adult $\mathrm{CB}$. This contrasts with the association between self-reported allergy and adult $\mathrm{NCB}$, in the absence of chronic airflow limitation $(\mathrm{n}=127, P=0.003)$. The estimates for obstructive $\mathrm{CB}$ were overlapping and imprecise; however, the OR was at least 3.1 for current smokers of $<20$ pack-years $(P=0.009)$; at least 9.6 for current smokers with a history of $\geq 20$ pack-years $(P<0.001)$, and at least 2.5 for those with current asthma $(P<0.001)$. This pattern remained following adjustment for childhood bronchitis (data not shown).

There was neither an asthma-smoking interaction on this obstructive $\mathrm{CB}$ phenotype related to few numbers $(\mathrm{n}=22)$ nor synergy between current smoking and allergy history with regard to NCB.

\section{Discussion}

This is a prospective study of a Caucasian population who were born in 1961, for whom we have longitudinal data from 1968 with regard to CB from childhood through to mid-adult 
Table 5 Relative associations between adult smoking, asthma, and allergy on airflow obstruction, CB, and its overlap

\begin{tabular}{|c|c|c|c|}
\hline \multirow{2}{*}{$\begin{array}{l}\text { Clinical characteristics } \\
\text { in middle age }\end{array}$} & \multicolumn{3}{|c|}{ The CB-COPD overlap $\left(\mathrm{N}=\mathrm{I}, 307\right.$, adjusted OR $\left.[95 \% \mathrm{Cl}]^{\mathrm{a}}\right)$} \\
\hline & $\begin{array}{l}\text { Spirometrically defined } \\
\text { COPD only }(n=95)\end{array}$ & Nonobstructive CB (n=|27) & Obstructive CB $(n=22)$ \\
\hline \multicolumn{4}{|l|}{ Personal smoking* } \\
\hline None & I & 1 & I \\
\hline Past $<20$ pack-years & $0.96(0.49,1.86)$ & $1.27(0.76,2.12)$ & $2.08(0.13,33.6)$ \\
\hline Past $>20$ pack-years & $2.11(0.86,5.14)$ & $0.83(0.28,2.40)$ & $9.67(0.59,160)$ \\
\hline Current $<20$ pack-years & $1.97(0.98,3.95)$ & $\mathrm{I} .30(0.67,2.5 \mathrm{I})$ & $19.5(2.13,179)^{* *}$ \\
\hline Current $>20$ pack-years & $4.89(2.73,8.76)^{* * * *}$ & $4.31(2.58,7.18)^{* * *}$ & $76.3(9.56,609)^{* * *}$ \\
\hline \multicolumn{4}{|l|}{ Asthma/wheezy breathing* } \\
\hline Never & I & 1 & 1 \\
\hline Remitted & $1.05(0.56,1.98)$ & $0.71(0.44,1.14)$ & $3.64(0.42,31.3)$ \\
\hline Current & $4.93(2.68,9.07)^{* * * *}$ & $1.55(0.93,2.58)$ & $20.6(2.53,167)^{* *}$ \\
\hline Allergy history & $1.12(0.68,1.84)$ & $1.94(1.24,3.03)^{* *}$ & $2.00(0.66,6.08)$ \\
\hline
\end{tabular}

Notes: Those with missing data were excluded from individual analyses. ${ }^{\text {aAll }}$ exposure variables are adjusted for one another; $*$ Univariable $P$ for trend across ordered groups $<0.001$; $* * P<0.01$; *** $P<0.001$.

Abbreviations: $\mathrm{CB}$, chronic bronchitis; $\mathrm{Cl}$, confidence interval; COPD, chronic obstructive pulmonary disease; OR, odds ratio.

life. We confirmed the strength of association between current asthma and adult $\mathrm{CB}$ was at least as high as the estimate for current smokers with at least 20 pack-years history. Although the associations with self-reported allergy were lower, they were still statistically significant, and this contrasted with the lack of association for former smokers. We also found associations between personal smoking, current asthma, and chronic airflow limitation both in the presence and absence of adult $\mathrm{CB}$. This contrasts with self-reported allergy, which was only associated with adult NCB. Although childhood bronchitis was not found to impact upon $\mathrm{CB}$ in adults, our data have shown childhood allergy, childhood episodic asthma, as well as parental bronchitis to be relevant clinical predictors. We found no evidence of an independent association between current atopy measured by skin prick testing and adult CB.

"Asthma" as a cause of adult CB is often overlooked in adult clinical practice, despite its inclusion in major clinical guidelines. ${ }^{2}$ Its potential as a risk factor has been illustrated by the Tucson Epidemiologic Study of Airway Obstructive Diseases, in which "active" physician-diagnosed asthma was associated with a ten-fold increase in incident adult $\mathrm{CB}$ over a period of 20 years. ${ }^{21}$ Although our findings are consistent with this relationship, we also confirmed a history of multiple allergies to be associated with $\mathrm{CB}$ in middle age. This link between allergy history and adult CB is similar to data from the National Population Health Survey of middle-aged Canadian adults $(\mathrm{n}=7,710) .{ }^{22}$ The Tucson study also showed a lack of association with objective measures such as atopic sensitization or serum immunoglobulin $\mathrm{E}$ level measured at baseline, ${ }^{21}$ and this is consistent with our findings. This reflects potential methodological differences between objective skin prick testing and subjective recall of an allergic history as adults. On the one hand, atopic sensitization may not be representative of clinical illness, and skin prick test positivity can wane with increasing age. On the other hand, subjective recall by adults can be frequently inaccurate with a tendency to reflect more severe cases, or possibly, postnasal drip from nonallergic rhinitis may be mislabeled as hay fever.

We found the strongest association between adult $\mathrm{CB}$ and current asthma, even when compared with current cigarette smokers with at least a 20-pack-year history. The significant but lesser associations for allergic history still suggest that a role for asthma and allergy has been underappreciated. Like smoking, we have found preliminary evidence to suggest current asthma to be associated with obstructive $\mathrm{CB}$, in contrast to an allergic history that was associated with NCB. The allergic mechanism most likely relates to T-helper type 2 inflammation in the asthmatic airway, as interleukins-4 and -13 (or T-helper type 2 cytokines) from the allergic response have been linked to chronic mucus hypersecretion. ${ }^{23}$ Similar to tobacco smoking, ${ }^{10}$ these data raise the possibility that chronic mucus hypersecretion from symptomatic asthma might be a potential marker for early chronic airflow limitation in mid-adult life.

Early-life factors for COPD are increasingly being recognized, ${ }^{24}$ but there has not been a similar emphasis or interest for adult CB. In this study, we have documented a relationship between childhood asthma and/or allergy and the occurrence of adult CB in mid-adult life, although null relationships were seen for some asthma severity categories that contained few numbers. It is important to note that our participants with asthma were born in 1961, which was a time before the widespread use of inhaled corticosteroid therapy, and so our estimates may be greater than those seen 
for children with asthma belonging to more recent generations. More data are needed to assess the relevance of the occurrence of early life asthma and allergy to individuals presenting in middle-to-older age with symptoms consistent with CB.

A positive association with adult $\mathrm{CB}$ was also seen for parental bronchial symptoms noted when participants were aged only 7 years old, and this contrasts the lack of association with recurrent cough at that time in the children themselves. This was an unexpected null finding, although there were relatively few with chronic childhood symptoms. Although hereditary causes of adult CB have been recognized for several decades, ${ }^{7}$ there are few data that quantify the strength of an association. In one study of 44 probands with severe, early-onset, non- $\alpha$-1-antitrypsin deficiency-related COPD, the proportion of first-degree relatives who reported smoking-related CB was significantly higher than age- and sex-matched control smoking subjects despite similar pack-year histories (30\% versus 13\%). ${ }^{25}$ This genotypeby-smoking interaction supports a familial predisposition relating to adult $\mathrm{CB}$.

Our finding of a lack of association with adult CB for past smokers is not widely documented, ${ }^{2}$ but may be consistent with simple (or mucoid) bronchitis being the predominant form of adult $\mathrm{CB}$ in this subgroup. This form is reversible in most smokers, with a reduction in expectoration occurring when an individual quits smoking. ${ }^{9}$ The null finding for an asthmasmoking interaction with regard to obstructive CB most likely relates to insufficient power from few case numbers.

The major strength of our study was the prospectively collected data from a large population-based sample, where twothirds of the original cohort $(n=8,583)$ responded 37 years later to the 2004 postal survey $(n=5,729)$. Our results with a relatively low attrition rate may be more representative of the general population than most other studies. In terms of our definition for adult $\mathrm{CB}$, we adopted a series of questions using the term "bring up phlegm" in line with the original description, ${ }^{1}$ and this structure provides greater consistency than responses to a single question. We acknowledge that our questions and others used by other major epidemiological studies ${ }^{26,27}$ might not identify those who have a tendency to swallow their mucus and so not report expectoration, ${ }^{5}$ which effectively biases our estimates toward the null.

This study also had limitations. First, the analytical design of the 2004 postal survey to all eligible participants did not include spirometric data, except for a subsequent subset. Therefore, we were unable to provide regression estimates for those with and without CB-associated COPD for the entire group. Similarly, as this was a whole-of-population study, it was not feasible to perform high-resolution computed tomography and identify the expected small number of participants with bronchiectasis. Nor was there exposure data from 2004 to examine for the potential confounding effect of ambient air pollution. Second, the assessment of $\mathrm{CB}$ was limited to questionnaire data from childhood to middle age, with different definitions used at these time points, so the natural history of $\mathrm{CB}$ could not be examined. Third, a history of allergy would be subject to recall bias, such that milder cases may not be recalled. Adults with respiratory symptoms such as $\mathrm{CB}$ may have the tendency to recollect more information, which might have a variable influence on the estimates. Fourth, the estimates for the CB-COPD overlap analysis are imprecise due to relatively fewer participants in the questionnaire phase having post-BD spirometry. Fifth, as our participants were almost exclusively Caucasian in ethnicity and in their mid-forties, this might limit the generalizability of our findings to other populations.

\section{Conclusion}

The independent associations between current asthma, selfreported allergy, and adult $\mathrm{CB}$, regardless of post-BD airflow obstruction, suggest a greater contribution from asthma and allergy than previously thought. The identification of childhood allergic history, childhood asthma, and parental bronchitis symptoms, as clinical predictors of adult $\mathrm{CB}$, raises the possibility of some of this burden having origins in childhood. Our findings that examined spirometrically defined COPD and adult $\mathrm{CB}$ separately and in combination also raise the possibility for different roles of asthma and allergy. CB in adults, even if not associated with airway obstruction, is linked to considerable morbidity and possible mortality. A better understanding of NCB and obstructive CB will optimize the approach for its prevention, diagnosis, and treatment. ${ }^{6}$

\section{MeSH terms}

Epidemiology [H02.403.720.500]

Bronchitis, Chronic [C08.127.446.567]

Bronchitis, Chronic [C08.381.495.146.567]

Bronchitis, Chronic [C08.381.495.389.500]

Bronchitis, Chronic [C08.730.099.567]

\section{Acknowledgments}

We acknowledge the TAHS study participants and previous investigators, Drs Heather Gibson, Bryan Gandevia, Harold Silverstone, and Norelle Lickiss. We thank the TAHS investigators who are not coauthors of this manuscript, Prof 
Mark Jenkins, Assoc Prof Stephen Morrison, Dr Iain Feather, and Dr Adrian Lowe, for their assistance including obtaining funds and data collection. We also acknowledge all the respiratory scientists who collected data in the lung function laboratories of Tasmania, Victoria, Queensland, and New South Wales; the research interviewers and data entry operators; and the organizational roles of Ms Cathryn Wharton and Dr Desiree Mészáros. Finally, we thank the Archives Office of Tasmania for providing data from the 1968 and 1974 TAHS questionnaires and copies of the school medical records.

This study was supported by the National Health and Medical Research Council of Australia, research grant 299901; The University of Melbourne; Clifford Craig Medical Research Trust of Tasmania; the Victorian, Queensland \& Tasmanian Asthma Foundations; The Royal Hobart Hospital; Helen MacPherson Smith Trust; GlaxoSmithKline; and JLH. SCD, MCM, AJL, EHW, JAB, and JLH are supported by the NHMRC of Australia. JLP is supported by the Center for Air quality and health Research evaluation (CAR), which is also funded by the NHMRC of Australia.

\section{Author contributions}

SCD and JLP confirm they are equal first authors and equal legal and equitable owners of the paper and fully capable of granting the Exclusive License to Dove Medical Press Limited and entering into the agreement to publish this manuscript as an open access paper. EHW and MCM should be considered as equal senior authors. Study concept and design: SCD, EHW, MJA, DPJ, GGG, JLH; Acquisition of data: SCD, EHW, MJA, MCM, PST, DPJ; Analysis and interpretation of data: JLP, SCD, MJA, EHW, JAB, CJL; Drafting of the manuscript: JLP, SCD, MJA, EHW, MCM, JAB, CJL; Critical revision of the manuscript for important intellectual content: all authors; Statistical analysis: JLP, SCD; Obtained funding: SCD, EHW, MJA, DPJ, JLH; Administrative, technical and material support: SCD; Study supervision: SCD, EHW, MCM, DPJ, MJA.

\section{Disclosure}

EHW and DPJ have received honoraria from GlaxoSmithKline for giving lectures; MJA has received investigator initiated grants for unrelated research from Pfizer and BoehringerIngelheim, a consultancy from AstraZeneca and conference support from Boehringer-Ingelheim and Sanofi. The funding agencies had no direct role in the conduct of the study, the collection, management, statistical analysis, and interpretation of the data, preparation, or approval of the manuscript. The authors report no other conflicts of interest in this work.

\section{References}

1. Definition and classification of chronic bronchitis for clinical and epidemiological purposes. A report to the Medical Research Council by their Committee on the Aetiology of Chronic Bronchitis. Lancet. 1965; 1(7389):775-779.

2. Braman SS. Chronic cough due to chronic bronchitis: ACCP evidence-based clinical practice guidelines. Chest. 2006;129(1 Suppl): 104S-115S.

3. Global Strategy for the Diagnosis, Management, and Prevention of Chronic Obstructive Pulmonary Disease: Global Initiative for Chronic Obstructive Lung Disease. Updated 2014. Available from: http:// goldcopd.org. Accessed April 19, 2014.

4. Mannino DM, Buist AS, Petty TL, Enright PL, Redd SC. Lung function and mortality in the United States: data from the First National Health and Nutrition Examination Survey follow up study. Thorax. 2003;58(5): 388-393.

5. Vestbo J, Hogg JC. Convergence of the epidemiology and pathology of COPD. Thorax. 2006;61(1):86-88.

6. National Heart, Lung, and Blood Institute. Non-obstructive Chronic Bronchitis. Executive Summary; 2011. Available from: http://www.nhlbi. nih.gov/research/reports/2011-bronchitis. Accessed June 5, 2016.

7. Aetiology of chronic bronchitis. Br Med J. 1956;1(4972):906-907.

8. Holland WW. Evidence for the implication of environmental factors in the aetiology of chronic bronchitis. Z Erkr Atmungsorgane. 1983; 161(2):130-137.

9. Fletcher CM. Bronchitis and emphysema: classification and pathogenesis. Proc R Soc Med. 1962;55:451-453.

10. Allinson JP, Hardy R, Donaldson GC, Shaheen SO, Kuh D, Wedzicha JA. The presence of chronic mucus hypersecretion across adult life in relation to COPD development. Am J Respir Crit Care Med. 2015; 193(6):662-672.

11. Wharton C, Dharmage S, Jenkins M, et al. Tracing 8,600 participants 36 years after recruitment at age seven for the Tasmanian Asthma Study. Aust N Z J Public Health. 2006;30(2):105-110.

12. Gibson HB, Silverstone H, Gandevia B, Hall GJ. Respiratory disorders in seven-year-old children in Tasmania. Aims, methods and administration of the survey. Med J Aust. 1969;2(4):201-205.

13. Giles GG, Lickiss N, Gibson HB, Shaw K. Respiratory symptoms in Tasmanian adolescents: a follow up of the 1961 birth cohort. Aust NZJ Med. 1984;14(5):631-637.

14. Jenkins MA, Hopper JL, Bowes G, Carlin JB, Flander LB, Giles GG. Factors in childhood as predictors of asthma in adult life. BMJ. 1994; 309(6947):90-93.

15. Burgess JA, Walters EH, Byrnes GB, et al. Who remembers whether they had asthma as children? J Asthma. 2006;43(10):727-730.

16. Perret JL, Dharmage SC, Matheson MC, et al. The interplay between the effects of lifetime asthma, smoking, and atopy on fixed airflow obstruction in middle age. Am J Respir Crit Care Med. 2013;187(1):42-48.

17. Perret JL, Walters EH, Johns DP, et al. Mother's smoking and complex lung function of offspring in middle age: a cohort study from childhood. Respirology. In press.

18. Quanjer PH, Stanojevic S, Cole TJ, et al. Multi-ethnic reference values for spirometry for the 3-95-yr age range: the global lung function 2012 equations. Eur Respir J. 2012;40(6):1324-1343.

19. Quanjer PH, Pretto JJ, Brazzale DJ, Boros PW. Grading the severity of airways obstruction: new wine in new bottles. Eur Respir J. 2014; 43(2):505-512.

20. Jenkins MA, Clarke JR, Carlin JB, et al. Validation of questionnaire and bronchial hyperresponsiveness against respiratory physician assessment in the diagnosis of asthma. Int J Epidemiol. 1996;25(3): 609-616.

21. Silva GE, Sherrill DL, Guerra S, Barbee RA. Asthma as a risk factor for COPD in a longitudinal study. Chest. 2004;126(1):59-65.

22. Chen Y, Breithaupt K, Muhajarine N. Occurrence of chronic obstructive pulmonary disease among Canadians and sex-related risk factors. J Clin Epidemiol. 2000;53(7):755-761. 
23. Wardlaw AJ, Brightling CE, Green R, Woltmann G, Bradding P, Pavord ID. New insights into the relationship between airway inflammation and asthma. Clin Sci (Lond). 2002;103(2):201-211.

24. Svanes C, Sunyer J, Plana E, et al. Early life origins of chronic obstructive pulmonary disease. Thorax. 2010;65(1):14-20.

25. Silverman EK, Chapman HA, Drazen JM, et al. Genetic epidemiology of severe, early-onset chronic obstructive pulmonary disease. Risk to relatives for airflow obstruction and chronic bronchitis. Am J Respir Crit Care Med. 1998;157(6 Pt 1):1770-1778.
26. de Marco R, Accordini S, Anto JM, et al. Long-term outcomes in mild/ moderate chronic obstructive pulmonary disease in the European community respiratory health survey. Am J Respir Crit Care Med. 2009; 180(10):956-963.

27. Bridevaux PO, Gerbase MW, Probst-Hensch NM, Schindler C, Gaspoz JM, Rochat T. Long-term decline in lung function, utilisation of care and quality of life in modified GOLD stage 1 COPD. Thorax. 2008;63(9):768-774.

\section{Publish your work in this journal}

The International Journal of COPD is an international, peer-reviewed journal of therapeutics and pharmacology focusing on concise rapid reporting of clinical studies and reviews in COPD. Special focus is given to the pathophysiological processes underlying the disease, intervention programs, patient focused education, and self management protocols.

\section{Dovepress}

This journal is indexed on PubMed Central, MedLine and CAS. The manuscript management system is completely online and includes a very quick and fair peer-review system, which is all easy to use. Visit $\mathrm{http}: / / \mathrm{www}$.dovepress.com/testimonials.php to read real quotes from published authors. 